\title{
Poly(butylcyanoacrylate) and Poly( $\varepsilon$-caprolactone) Nanoparticles Loaded with 5-Fluorouracil Increase the Cytotoxic Effect of the Drug in Experimental Colon Cancer
}

\author{
Raúl Ortiz, ${ }^{1,2}$ Laura Cabeza, ${ }^{2}$ José L. Arias, ${ }^{2,3,4}$ Consolación Melguizo, ${ }^{2,4,5}$ Pablo J. Álvarez, ${ }^{4}$ Celia Vélez, ${ }^{2,4}$ \\ Beatriz Clares, ${ }^{3}$ Antonia Áranega, ${ }^{2,4}$ and Jose Prados ${ }^{2,4}$
}

\begin{abstract}
Received 28 November 2014; accepted 25 March 2015; published online 17 April 2015
ABSTRACT. The clinical use of 5-fluorouracil, one of the drugs of choice in colon cancer therapy, is limited by a nonuniform oral absorption, a short plasma half-life, and by the development of drug resistances by malignant cells. We hypothesized that the formulation of biodegradable nanocarriers for the efficient delivery of this antitumor drug may improve its therapeutic effect against advanced or recurrent colon cancer. Hence, we have engineered two 5-fluorouracil-loaded nanoparticulate systems based on the biodegradable polymers poly(butylcyanoacrylate) and poly(e-caprolactone). Drug incorporation to the nanosystems was accomplished by entrapment (encapsulation/dispersion) within the polymeric network during nanoparticle synthesis, i.e., by anionic polymerization of the monomer and interfacial polymer disposition, respectively. Main factors determining 5-fluorouracil incorporation within the polymeric nanomatrices were investigated. These nanocarriers were characterized by high drug entrapment efficiencies and sustained drug-release profiles. In vitro studies using human and murine colon cancer cell lines demonstrated that both types of nanocarriers significantly increased the antiproliferative effect of the encapsulated drug. In addition, both nanoformulations produced in vivo an intense tumor growth inhibition and increased the mice survival rate, being the greater tumor volume reduction obtained when using the poly( $\varepsilon$-caprolactone)-based formulation. These results suggest that these nanocarriers may improve the antitumor activity of 5-fluorouracil and could be used against advanced or recurrent colon cancer.
\end{abstract}

KEY WORDS: 5-fluorouracil; colon cancer; poly(butylcyanoacrylate); poly(e-caprolactone); polymeric nanoparticles.

\section{INTRODUCTION}

Colon cancer is one of the three most frequently diagnosed cancers (1). This severe disease has an excellent prognosis if it is diagnosed at an early stage. However, $25 \%$ of colon cancer patients develop metastasis, thus requiring chemotherapy which is frequently based on 5-fluorourcail (5-FU), a first line antitumor molecule (2). Unfortunately, patients in an advanced stage usually have a poor response to chemotherapy with a 5 -year survival rate of $10 \%$ (3).

Raúl Ortiz and Laura Cabeza contributed equally to this work.

${ }^{1}$ Department of Health Science, University of Jaén, 23071, Jaén, Spain.

${ }^{2}$ Institute of Biopathology and Regenerative Medicine (IBIMER), Department of Anatomy and Embryology, University of Granada, Avda. Conocimiento s/n, 18100, Granada, Spain.

${ }^{3}$ Department of Pharmacy and Pharmaceutical Technology, University of Granada, 18071, Granada, Spain.

${ }^{4}$ Biosanitary Institute of Granada (ibs.GRANADA), SASUniversidad de Granada, Granada, Spain.

${ }^{5}$ To whom correspondence should be addressed. (e-mail: melguizo@ugr.es)
5-FU can also be found in combined chemotherapy schedules, e.g., associated to irinotecan (a combination of irinotecan with 5-FU and folinic acid (FOLFIRI)), oxiplatin (a combination of oxaliplatin, 5-FU, and folinic acid (FOLFOX)), or to new drug molecules, e.g., epidermal growth factor receptor inhibitors and angiogenesis inhibitors. However, rapid metabolism, low accumulation into tumor tissues, systemic toxicity, and the development of resistances by malignant cells are frequently implicated in drug therapy failure (4-6). Thus, new therapeutic strategies are needed to overcome these limitations and to improve current colon cancer therapies.

In the context of cancer treatment, the use of nanoparticles (NPs; preferably $<100 \mathrm{~nm}$ ) as drug delivery systems can provide significant advantages over the use of free drug molecules. In fact, nanoparticulate systems can radically affect drug biodistribution, therefore increasing drug concentration and specificity toward malignant tissues. Additionally, NPs can prolong the plasma half-life of cytotoxic drugs while keeping to a (very) minimum the associated drug toxicity (7). Interestingly, these nanosystems have been further described to overcome drug resistances developed by tumor cells, thereby significantly increasing the drug accumulation within 
these cells (8). Furthermore, tumor-selective drug targeting can be possible by formulating nanocarriers appropriately surface functionalized with targeting molecules (9).

In the specific case of colon cancer, many types of polymeric NPs have been proposed to optimize drug therapy (10). Amongst them, poly(butylcyanoacrylate) (PBCA) and poly( $\varepsilon$-caprolactone) (PCL) NPs may be of significant interest given their biodegradable and biocompatible character, coupled with their capacity to extend the plasma half-life of drug molecules while reducing their unspecific cytotoxicity $(7,11,12)$. For instance, PCL NPs have been satisfactorily loaded with different drug molecules, e.g., gemcitabine (13), doxorubicin (14), and ftorafur (15). Recently, 5-FU-loaded PCL NPs have been engineered as injectable anticancer implants (16), intraperitoneally administered against peritoneal carcinomatosis (17), and associated with suicide gene therapy against colon cancer (18). Regarding PBCA NPs, they have been loaded with curcumin (19), paclitaxel $(20,21)$, and gemcitabine (22) for the efficient treatment of different types of cancer. In this line, poly(alkylcyanoacrylate) NPs adequately surface functionalized have been described to bypass the blood-brain barrier, thus demonstrating significant potential for the delivery of antitumor agent against brain malignancies (23-25). Furthermore, poly(alkylcyanoacrylates) can overcome drug resistances developed by cancer cells (26). Unfortunately, neither PCL nor PBCA nanoparticulate systems have been properly analyzed as potential tools in drug delivery against colon cancer.

In this study, we report the synthesis and characterization of two 5-FU-loaded biodegradable NPs based on PBCA and PCL and synthesized by anionic polymerization of the monomer and interfacial polymer disposition methodologies, respectively. Four colon cancer cell lines and a normal colon cell line were used to investigate the in vitro antiproliferative activity of both types of 5-FU-loaded NPs in comparison with the free drug. In addition, in vivo tumor growth inhibition, survival, and toxicity were evaluated in immunocompetent C57BL/6 mice.

\section{MATERIALS AND METHODS}

\section{Materials}

All chemicals were of analytical quality from SigmaAldrich Chemical Co. (Spain). Butylcyanoacrylate is a generous gift from Henkel Loctite (Ireland).

Synthesis of 5-Fluorouracil Nanocarriers Based on Poly(butylcyanoacrylate) and Poly( $\varepsilon$-caprolactone)

PBCA NPs were formulated by emulsion polymerization of the butylcyanoacrylate monomer in an aqueous solution (22). Briefly, $1 \mathrm{~mL}$ of an acetone solution of the monomer $(10 \%, w / v)$ was added drop-wise, under mechanical stirring $(10,000 \mathrm{rpm})$, to $10 \mathrm{~mL}$ of an aqueous solution containing $10^{-4} \mathrm{~N} \mathrm{HNO}_{3}$ and the stabilizing agent dextran-70 $(0.5 \%$, $w / v)$. After $6 \mathrm{~h}$, polymerization was terminated by neutralization of the aqueous medium with sufficient amount of a $\mathrm{KOH} 0.1 \mathrm{M}$ aqueous solution.

PCL NPs were synthesized by interfacial polymer disposition $(18,27)$. In a few words, $5 \mathrm{~mL}$ of a dichloromethane solution of the polymer $(2 \%, w / v)$ were incorporated drop-wise, under mechanical stirring $(10,000 \mathrm{rpm})$, to $25 \mathrm{~mL}$ of an aqueous solution containing dextran-70 $(0.5 \%, w / v)$. Mechanical stirring was continued for $3 \mathrm{~h}$ to assure the complete precipitation of the polymeric particles.

5-FU entrapment into PBCA and PCL NPs was based on the previously described preparation methodologies with the following additional steps: $(i)$ preparing the aqueous medium with increasing concentrations of the anticancer drug (up to $0.01 \mathrm{M}$ ), and then adding drop-wise the organic solution of the monomer (or polymer in the case of PCL); or, alternatively, (ii) preparing the aqueous medium, followed by the drop-wise incorporation of an organic solution of the monomer (or polymer in the case of PCL) containing adequate quantities of 5-FU (up to $0.01 \mathrm{M}$ ). Both procedures aimed to optimize the drug-loading efficacy to the NPs; concretely, the influence of including 5-FU molecules in the organic phase (in direct contact with the polymer PCL or the monomer butylcyanoacrylate) or in the aqueous media was analyzed. The aim of this study was to clarify whether the inclusion of the active agent in the phase where the polymer/ monomer is dissolved will minimize drug escape to the aqueous media, thus maximizing the drug-loading efficiencies. In fact, it is expected that drug incorporation into this organic phase will maximize the contact between the polymer PCL (or butylcyanoacrylate monomer) and the active agent, thus making possible greater 5-FU-loading (and entrapment) efficiencies. Solvents used in this study were the ones employed in the best NP preparation conditions (acetone to dissolve the butylcyanoacrylate monomer and dichloromethane to dissolve PCL). 5-FU was found to be freely soluble in acetone $(43 \mathrm{mg} / \mathrm{mL})$ and in dichloromethane $(52 \mathrm{mg} / \mathrm{mL})$.

The influence of the concentration of stabilizing agent and monomer (or polymer in the case of PCL) on 5-FU entrapment was also investigated. To that aim, the amount of monomer (or polymer in the case of PCL) added to the organic (or aqueous) solution was varied from 0.1 to $1 \mathrm{~g}$, and the concentration of stabilizing agent in the aqueous phase was varied between $0 \%$ and $3 \%(w / v)$. The production performance (yield, \%) of all the formulation conditions was determined:

Yield $(\%)$
$=\frac{\text { mass of nanoparticles loaded with drug }(\mathrm{mg})}{\text { mass of materials used in the synthesis of the nanoparticles }(\mathrm{mg})} \times 100$

Finally, in all cases, the final step of the preparation procedure involved the complete evaporation of the organic solvent (acetone in the case of PBCA or dichloromethane in the case of PCL) by using a BuchiRotavapor ${ }^{\circledR}$ rotary evaporator (Büchi Labortechnik AG, Flawil, Switzerland) (working at a prefixed temperature of $37^{\circ} \mathrm{C}$ ) to obtain the whitish aqueous NP dispersion. The colloid was then subjected to a cleaning process involving subsequent cycles of centrifugation ( $25 \mathrm{~min}$ at $11,000 \mathrm{rpm}$; Centrikon T-124 high-speed centrifuge, Kontron, France) and re-dispersion in water, until the conductivity of the supernatant was $<10$ $\mu \mathrm{S} / \mathrm{cm}$.

The nanoformulations were prepared under aseptic conditions in a sterile laminar flow hood, and attention was paid to avoid the contamination of the samples by external environment during manufacture and prior to injection into 
animals. In brief, a direct path was maintained between the filter and the area inside the hood where the nanosystems were prepared. Waste and other items never entered the hood. Hands and arms were washed before compounding or re-entering the hood and were kept within the cleaned area of the hood. Spraying or squirting solutions onto the high efficiency particulate air (HEPA) filter was avoided. Outer pouches and wraps were removed at the edge of the work area. Before and after preparing the nanoformulations, the work surface of the hood was thoroughly cleaned with alcohol.

\section{Characterization Methods}

Mean particle diameter ( \pm standard deviation) was determined in triplicate at $25.0 \pm 0.5^{\circ} \mathrm{C}$ by photon correlation spectroscopy (PCS; Malvern Autosizer ${ }^{\circledR}$ 4700, Malvern Instruments Ltd., UK). The scattering angle was set at $60^{\circ}$, and the measurement was made after suitable dilution of the aqueous NP dispersions $(\approx 0.1 \%, w / v)$ with an aqueous solution containing dextran-70 $(0.5 \%, w / v)$. The stability of the nanoformulations was evaluated by measuring both the size and 5-FU loading values after 3 months of storage at 4.0 $\pm 0.5^{\circ} \mathrm{C}$ in water.

In order to corroborate the size measurements, dilute aqueous NP dispersions $(\approx 0.1 \%, w / v)$ were observed by highresolution transmission electron microscopy (HRTEM; set at $80 \mathrm{kV}$ accelerating voltage; Stem Philips CM20 HighResolution Transmission Electron Microscope, The Netherlands). Prior to observation, the dispersions were sonicated during $3 \mathrm{~min}$, and drops were placed on copper grids with formvar film. The grids were then dried at $25.0 \pm 0.5^{\circ} \mathrm{C}$ in a convection oven.

Ultraviolet (UV) absorbance measurements (8500 UVvis Dinko Spectrophotometer, Dinko, Spain) were carried out in triplicate at the maximum absorbance wavelength $(266 \mathrm{~nm})$ to determine the 5-FU concentration in all the nanoformulations. To that aim, quartz cells of $1 \mathrm{~cm}$ path length were used. A good linearity between UV absorbance values and drug concentration up to $0.4 \mathrm{mM}$ was observed. The molar absorbance coefficient $\left(7300 \pm 100 \mathrm{~L} \mathrm{~mol}^{-1} \mathrm{~cm}^{-1}\right)$ used in these measurements was calculated from the leastsquare fitting of the data obtained in an UV absorbance/5-FU concentration calibration curve. The anticancer drug was found to be stable in $\mathrm{pH} 7.4$ phosphate-buffered saline (PBS), and the validity of the molar absorption coefficient at $266 \mathrm{~nm}$ was verified by UV absorbance determinations at this $\mathrm{pH}$.

Prior to the quantification of the amount of 5-FU loaded to (or released from) the polymeric NPs, the UV spectrophotometric method of analysis was validated and verified. Concretely, the method was validated by comparing the evaluation of drug concentration in two instances: a certain drug amount was dissolved in supernatants of NP syntheses (carried out in absence of 5-FU), and the same amount was dissolved in equal amounts of water. It was found that the drug concentrations estimated (in the first case from the difference between the absorbance of the drug plus supernatant solution and that of the supernatant) were identical to within the experimental uncertainty. These tests were done in sextuplicate and demonstrated the accuracy, precision, and linearity of the method and the absence of molecular interactions. In addition, the experimental uncertainty of the UV absorbance measurements was $<5 \%$.

Finally, the electrokinetic characteristics of both blank (drug-unloaded) and drug-loaded NPs were determined by electrophoresis measurements in water $(\approx 0.1 \%(w / v) \mathrm{NP}$ concentration) at $25.0 \pm 0.5^{\circ} \mathrm{C}$ (Malvern Zetasizer ${ }^{\circledR} 2000$ Electrophoresis Device, Malvern Instruments Ltd., UK). These determinations were done after $24 \mathrm{~h}$ of contact of NPs in water (at pH 6 and $1 \mathrm{mM} \mathrm{KNO}_{3}$ ) under mechanical stirring $(50 \mathrm{rpm})$ at this temperature. The experimental uncertainty of the measurements was $<5 \%$. The theory of O'Brien and White (28) was used to convert the electrophoretic mobility $\left(u_{\mathrm{e}}\right)$ into zeta potential $(\zeta)$ values. Such electrokinetic characterization was expected to confirm the type of 5-FU loading (adsorption onto the particle surface or entrapment into the matrix).

\section{5-Fluorouracil Loading Studies}

Measurement of the amount of drug loaded to the NPs was done in triplicate by UV spectrophotometric determinations of the 5-FU remaining in the aqueous solution (being obtained upon filtration of the nanoparticulate dispersion through a membrane filter; pore size, $0.1 \mu \mathrm{m}$ ) which was deduced from the total amount of drug in the aqueous NP dispersion. 5-FU incorporation to the NPs was expressed in terms of drug entrapment efficiency (\%) and drug loading (\%):

$$
\begin{aligned}
& \text { Drug entrapment efficiency }(\%) \\
& =\frac{\text { mass of drug incorporated in the NP matrix }(\mathrm{mg})}{\text { mass of drug used in the experiment }(\mathrm{mg})} \times 100
\end{aligned}
$$

$$
\begin{aligned}
& \text { Drug loading }(\%) \\
& =\frac{\text { mass of drug incorporated in the NP matrix }(\mathrm{mg})}{\text { mass obtained of NPs loaded with drug }(\mathrm{mg})} \times 100
\end{aligned}
$$

For the method to be accurate, we considered the contribution to the absorbance of sources other than variations in 5-FU concentration (e.g., the surfactant agent dextran-70), by subtracting the absorbance of the supernatant produced in the same conditions but without the anticancer drug.

\section{5-Fluorouracil In Vitro Release Studies}

5-FU release experiments were performed in triplicate following the dialysis bag method and using polymeric NPs with the greater drug-loading values, i.e., $\approx 9.6 \%$ for PBCA NPs (Table I), and $\approx 26.8 \%$ for PCL NPs (Table II). These are the nanoformulations that were investigated in vitro and in vivo. The release medium was PBS $(\mathrm{pH}=7.4 \pm 0.1)$ at $37.0 \pm$ $0.5^{\circ} \mathrm{C}$. Briefly, the bags were soaked in water at $25.0 \pm 0.5^{\circ} \mathrm{C}$ during $10 \mathrm{~h}$ before use. The dialysis bag with a cut-off of 2000 Da (Spectrum ${ }^{\circledR}$ Spectra/Por ${ }^{\circledR} 6$ Dialysis Membrane Tubing, USA) retained the NPs but permitted the free 5-FU to diffuse into the receiving phase (PBS, $\mathrm{pH}$ 7.4). Practically, $3 \mathrm{~mL}$ of 5-FU-loaded PBCA (or PCL) NP dispersion 
Table I. Effect of the Formulation Conditions (5-FU, Butylcyanoacrylate Monomer, and Dextran-70 Concentrations) for Drug Absorption on Particle Size, 5-FU Entrapment Efficiency (\%), 5-FU Loading (\%), and Zeta Potential ( $\zeta, \mathrm{mV})$ Values of the Blank (5-FU Unloaded) PBCA NPs and the 5-FU-Loaded PBCA NPs Synthesized After Drug Dissolution in the Organic Phase

\begin{tabular}{|c|c|c|c|c|c|c|}
\hline $\begin{array}{l}5-\mathrm{FU} \\
(\mathrm{M})\end{array}$ & $\begin{array}{l}\text { Butylcyanoacrylate } \\
(\%, w / v)\end{array}$ & $\begin{array}{l}\text { Dextran-70 } \\
(\%, w / v)\end{array}$ & Size (nm) & $\begin{array}{l}\text { 5-FU entrapment } \\
\text { efficiency }(\%)\end{array}$ & 5-FU loading (\%) & $\zeta(\mathrm{mV})$ \\
\hline 0 & 10 & 0.5 & $75 \pm 10$ & - & - & $-25 \pm 4$ \\
\hline $10^{-4}$ & 10 & 0.5 & $66 \pm 13(75 \pm 10)$ & $43.5 \pm 4.2(36.3 \pm 2.1)$ & $0.057 \pm 0.005(0.047 \pm 0.003)$ & $-28 \pm 2(-26 \pm 3)$ \\
\hline $10^{-3}$ & 10 & 0.5 & $87 \pm 10(77 \pm 13)$ & $64.9 \pm 3.6(52.7 \pm 2.2)$ & $0.84 \pm 0.05(0.69 \pm 0.03)$ & $-25 \pm 5(-24 \pm 2)$ \\
\hline $10^{-2}$ & 10 & 0.5 & $81 \pm 11(78 \pm 15)$ & $73.8 \pm 3.4(59.3 \pm 3.6)$ & $9.59 \pm 0.44(7.71 \pm 0.47)$ & $-26 \pm 3(-23 \pm 4)$ \\
\hline $10^{-2}$ & 10 & 0 & Macroaggregates & $3.1 \pm 1.3(2.6 \pm 1.2)$ & $0.41 \pm 0.17(0.34 \pm 0.16)$ & $-27 \pm 2(-25 \pm 3)$ \\
\hline $10^{-2}$ & 10 & 1 & $74 \pm 15(69 \pm 11)$ & $72.2 \pm 1.9(58.7 \pm 4.8)$ & $9.39 \pm 0.25(7.64 \pm 0.62)$ & $-29 \pm 6(-27 \pm 4)$ \\
\hline $10^{-2}$ & 10 & 2 & $64 \pm 12(84 \pm 13)$ & $75.4 \pm 3.9(60.1 \pm 2.7)$ & $9.81 \pm 0.51(7.82 \pm 0.35)$ & $-25 \pm 1(-23 \pm 5)$ \\
\hline $10^{-2}$ & 10 & 3 & $68 \pm 10(73 \pm 12)$ & $69.9 \pm 4.6(56.7 \pm 5.1)$ & $9.09 \pm 0.59(7.38 \pm 0.66)$ & $-26 \pm 2(-27 \pm 1)$ \\
\hline $10^{-2}$ & 50 & 0.5 & $84 \pm 11(76 \pm 10)$ & $71.4 \pm 2.8(58.2 \pm 3.3)$ & $1.86 \pm 0.07(1.51 \pm 0.08)$ & $-24 \pm 3(-26 \pm 4)$ \\
\hline $10^{-2}$ & 100 & 0.5 & $82 \pm 13(72 \pm 14)$ & $73.2 \pm 2.9(59.8 \pm 4.6)$ & $0.95 \pm 0.04(0.78 \pm 0.06)$ & $-28 \pm 3(-25 \pm 2)$ \\
\hline
\end{tabular}

Size, entrapment efficiency, and drug-loading values of 5-FU-loaded PBCA NPs obtained after drug dissolution in the aqueous media are set in italics

(containing $3 \mathrm{mg} / \mathrm{mL}$ of anticancer drug) were poured into the dialysis bag with the two ends fixed by clamps. The bag was then placed in a conical flask filled with $100 \mathrm{~mL}$ of the receiving phase and were stirred at $200 \mathrm{rpm}$. At different time intervals $(0.5,1,3,6,9,12,24,48,72,96$, and $120 \mathrm{~h}), 2 \mathrm{~mL}$ samples of the medium were withdrawn for UV spectrophotometric analysis at $266 \mathrm{~nm}$. An equal volume of the release medium, maintained at the same temperature, was added after sampling to ensure the sink conditions.

\section{Cell Culture}

Human colon cancer HT-29, T-84, and HCT-15 cell lines and the normal human colon CCD-18 cell line were obtained from the American Type Culture Collection (ATCC, USA). The mice colon cancer MC-38 cell line was kindly provided by Dr. J. Scholl (Public Health Service, National Institutes of Health, Bethesda, MD, USA). The cell lines were maintained in culture at $37^{\circ} \mathrm{C}$ (in a humidified $5 \% \mathrm{CO}_{2}$ incubator) in a Dulbecco's modified Eagle's medium (DMEM; Sigma-Aldrich, St.
Louis, MO, USA) supplemented with $10 \%$ heatinactivated fetal bovine serum (FBS) (Lonza, Walkersville, MD, USA) and $1 \%$ of an antibiotics mixture of penicillin $(10,000 \mathrm{U} / \mathrm{mL})$ and streptomycin $(10 \mathrm{mg} / \mathrm{mL})$.

\section{Proliferation Studies}

Cells were seeded in 24 -well plates $\left(8 \times 10^{3}\right.$ cells/well for T- 84 and MC-38, and $10 \times 10^{3}$ cells/well for HT-29, HCT-15, and CCD-18) in $300 \mu \mathrm{L}$ of supplemented DMEM. After $24 \mathrm{~h}$, treatments with 5-FU-loaded PBCA NPs and 5-FU-loaded PCL NPs were administered at concentrations ranging from 0.01 to $20 \mu \mathrm{M}$, depending on the cell line. Treatments with 5FU, blank PBCA NPs, and blank PCL NPs under the same conditions were used as controls. Untreated cells were used as negative control. Cells were maintained in culture during $72 \mathrm{~h}$, fixed with $300 \mu \mathrm{L}$ of trichloroacetic acid (TCA; 10\%) for $20 \mathrm{~min}$ at $4{ }^{\circ} \mathrm{C}$, and stained with $300 \mu \mathrm{L}$ of sulforhodamine B (SRB; 0.4\%) during $20 \mathrm{~min}$. After three washes with acetic acid (1\%), the dye was re-suspended in $10 \mathrm{mM}$ and $\mathrm{pH} 10.5$ Trizma ${ }^{\circledR}$, and a colorimetric assay was performed at $492 \mathrm{~nm}$

Table II. Effect of the Formulation Conditions (5-FU, PCL, and Dextran-70 Concentrations) for Drug Absorption on Particle Size, 5-FU Entrapment Efficiency (\%), 5-FU Loading (\%), and Zeta Potential $(\zeta, \mathrm{mV})$ Values of the Blank (5-FU Unloaded) PCL NPs and the 5-FULoaded PCL NPs Synthesized After Drug Dissolution in the Organic Phase

\begin{tabular}{lccllll}
\hline $\begin{array}{l}5-\mathrm{FU} \\
(\mathrm{M})\end{array}$ & $\begin{array}{l}\text { PCL } \\
(\%, w / v)\end{array}$ & $\begin{array}{l}\text { Dextran-70 } \\
(\%, w / v)\end{array}$ & Size $(\mathrm{nm})$ & $\begin{array}{l}\text { 5-FU entrapment } \\
\text { efficiency }(\%)\end{array}$ & 5-FU loading $(\%)$ & $\zeta(\mathrm{mV})$ \\
\hline 0 & 2 & 0.5 & $70 \pm 15$ & - & - & $-17 \pm 2$ \\
$10^{-4}$ & 2 & 0.5 & $76 \pm 12(77 \pm 15)$ & $55.2 \pm 4.6(41.4 \pm 3.9)$ & $0.18 \pm 0.02(0.14 \pm 0.01)$ & $-14 \pm 3(-15 \pm 2)$ \\
$10^{-3}$ & 2 & 0.5 & $67 \pm 14(70 \pm 12)$ & $74.6 \pm 3.1(59.2 \pm 3.4)$ & $2.43 \pm 0.11(1.92 \pm 0.11)$ & $-14 \pm 4(-16 \pm 3)$ \\
$10^{-2}$ & 2 & 0.5 & $79 \pm 16(65 \pm 15)$ & $82.4 \pm 4.2(66.5 \pm 3.3)$ & $26.8 \pm 1.4(21.6 \pm 1.1)$ & $-13 \pm 2(-17 \pm 2)$ \\
$10^{-2}$ & 2 & 0 & Macroaggregates & $3.7 \pm 1.2(2.3 \pm 1.6)$ & $1.21 \pm 0.39(0.75 \pm 0.52)$ & $-15 \pm 3(-14 \pm 4)$ \\
$10^{-2}$ & 2 & 1 & $73 \pm 12(81 \pm 14)$ & $84.2 \pm 3.9(67.2 \pm 2.8)$ & $27.4 \pm 1.3(21.8 \pm 0.9)$ & $-12 \pm 3(-12 \pm 2)$ \\
$10^{-2}$ & 2 & 2 & $64 \pm 17(84 \pm 12)$ & $80.3 \pm 3.2(64.6 \pm 3.1)$ & $26.1 \pm 1.1(21.1 \pm 1.1)$ & $-15 \pm 4(-14 \pm 2)$ \\
$10^{-2}$ & 2 & 3 & $74 \pm 19(71 \pm 16)$ & $78.2 \pm 2.6(61.3 \pm 4.2)$ & $25.4 \pm 0.8(19.9 \pm 1.4)$ & $-16 \pm 3(-15 \pm 3)$ \\
$10^{-2}$ & 10 & 0.5 & $70 \pm 10(68 \pm 13)$ & $81.6 \pm 3.7(65.2 \pm 3.2)$ & $5.31 \pm 0.24(4.24 \pm 0.21)$ & $-13 \pm 2(-12 \pm 3)$ \\
$10^{-2}$ & 20 & 0.5 & $75 \pm 15(72 \pm 17)$ & $85.1 \pm 4.1(69.4 \pm 2.8)$ & $2.77 \pm 0.13(2.26 \pm 0.09)$ & $-15 \pm 1(-16 \pm 2)$ \\
\hline
\end{tabular}

Size, entrapment efficiency, and drug-loading values of 5-FU-loaded PCL NPs obtained after drug dissolution in the aqueous media are set in italics 
(Titertekmultiscan Colorimeter, Flow, Irvine, CA, USA). The percentage of relative proliferation (RP; \%) was calculated as follows:

$\mathrm{RP}(\%)=\frac{\text { absorbance of the sample }}{\text { absorbance of the negative control }} \times 100$

The percentage of relative inhibition (RI; \%; which was used to determine the half maximal inhibitory concentration, $\mathrm{IC}_{50}$, value of the different treatments) was also calculated:

$\mathrm{RI}(\%)=100-\mathrm{RP}(\%)$

We make a nonlinear regression to determine the $\mathrm{IC}_{50}$ value with the software GraphPad Prism v.6.01.

\section{In Vivo Study}

Immunocompetent C57BL/6 female mice (body weight, 25-30 g; Scientific Instrumentation Centre, University of Granada, Spain) were maintained in a laminar airflow cabinet located in a room maintained at $37.0 \pm 0.5^{\circ} \mathrm{C}$ and $40-70 \%$ of relative humidity, with a 12 -h light/dark cycle, and under specific pathogen-free conditions. Work with animals was accomplished in accordance with institutional (Biomedical Investigation Ethic Committee, Virgen de las Nieves Hospital, Granada, Spain) and international standards (European Communities Council directive 86/609). Pilot experiments were previously conducted to determine the number of malignant cells for subcutaneous injection. Sixty mice were then inoculated by subcutaneous injection in the right hind flank with $5 \times 10^{5} \mathrm{MC}-38$ murine colon cancer cells per mouse dispersed in $200 \mu \mathrm{L}$ of PBS. This colon adenocarcinoma cell line was obtained from C57BL/6 mice, and therefore it can be used to induce subcutaneous tumors in the same immunocompetent mice strain. When tumors grew to $40-60 \mathrm{~mm}^{3}$, mice were randomly divided into six groups $(n=10)$ corresponding to the treatments with free 5-FU solution, blank PBCA NPs, blank PCL NPs, 5-FU-loaded PBCA NPs, and 5-FU-loaded PCL NPs. A group of untreated mice with subcutaneous tumor was used as negative control. 5-FU doses of $10 \mathrm{mg} / \mathrm{kg}$ of body mass were administered in all of the formulations containing the chemotherapy agent. Each mouse was intravenously injected every 3 days, up to a total number of five administrations. At the same time, body mass of mice (to define the toxicity of the treatments) and mice deaths (survival analysis) were recorded, and tumor volumes $\left(V ; \mathrm{mm}^{3}\right)$ were measured by using a digital caliper (29): measuring the largest diameter $a$ of the tumor mass and the second largest diameter $b$ perpendicular to $a$. The tumor volume was then calculated:

$V\left(\mathrm{~mm}^{3}\right)=\frac{a \cdot b^{2} \cdot \pi}{6}$

\section{Statistical Analysis}

All the results were represented as mean \pm standard deviation (SD). Logarithmic regressions were used to determine the $\mathrm{IC}_{50}$ values (GraphPad Prism version 6.01, GraphPad Software, Inc., La Jolla, CA, USA). Statistical analysis was performed by using the Student's $t$ test (SPSS v.15, SPSS, Chicago, USA). The probability of mice survival was determined by the Kaplan-Meier method, and the logrank test was used to compare the fraction of the surviving mice between groups $(\alpha=0.05)$. Data with $p<0.05$ and $p<0.001$ were considered as significant and highly significant, respectively.

\section{RESULTS}

\section{Particle Size, Surface Electrical Charge, and Stability}

PBCA NPs formulated by emulsion polymerization were characterized by a spherical shape and an average diameter under $100 \mathrm{~nm}$ (Table I; Fig. 1a). Similar results were obtained when PCL NPs were synthesized following an interfacial polymer disposition methodology (Table II; Fig. 1a). The surface electrical charge of PBCA NPs and PCL NPs was found to be negative in water (Tables I and II). This behavior can be associated to the degree of dissociation of the free acrylic groups (included in the chemical structure of the particles) under the experimental conditions (at pH 6 and $1 \mathrm{mM} \mathrm{KNO}_{3}$ ) (15,30). Neither particle size nor the quality of the polymeric suspensions varied considerably when different drug quantities were loaded onto either type of polymeric particles (Tables I and II). Neither 5-FU precipitation and/or release, presence of bulky sediments/aggregates, particle aggregation,
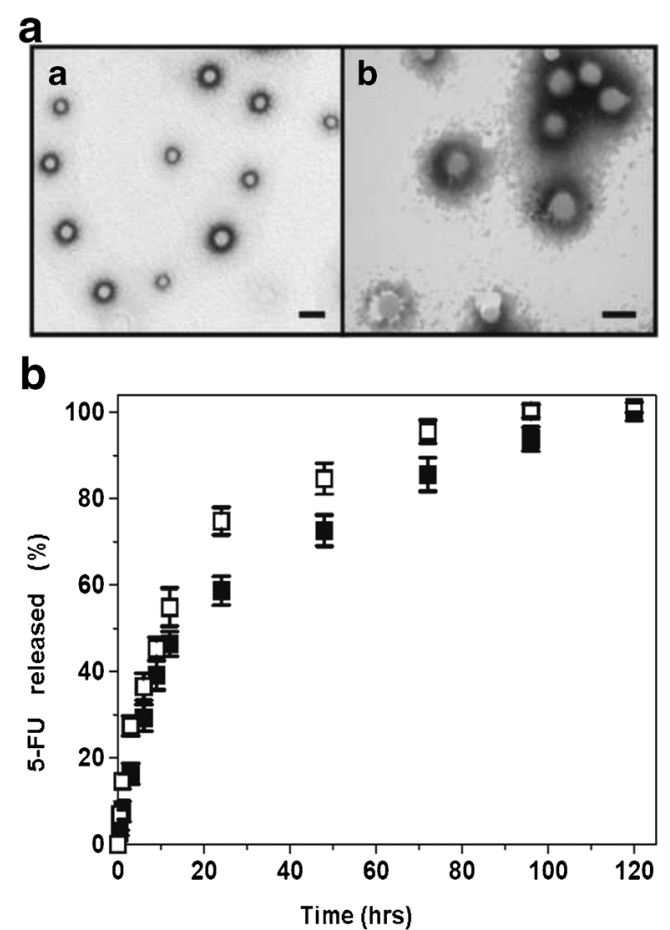

Fig. 1. 5-Fluorouracil-loaded NPs. a High-resolution transmission electron micrograph of PBCA $(a)$ and PCL (b) NPs. Bar lengths, $100 \mathrm{~nm}$. b Release of entrapped 5-FU from PBCA NPs (open squares) and PCL NPs (filled squares) as a function of the incubation time in PBS ( $\mathrm{pH} 7.4 \pm 0.1$ ) at $37.0 \pm 0.5^{\circ} \mathrm{C}$. Data represents the mean value $\pm \mathrm{SD}$ of quadruplicate experiences 
nor appreciable change in particle diameter and electrical surface charge were detected after 3 months of storage in water at $4.0 \pm 0.5^{\circ} \mathrm{C}$. Consequently, if the nanoformulations were not directly used after preparation, they were kept under these storage conditions until use.

\section{5-Fluorouracil Entrapment into Poly(butylcyanoacrylate) and Poly( $\varepsilon$-Caprolactone) Nanoparticles}

We began the investigation by analyzing the influence of the initial phase (aqueous or organic) in which 5-FU was dissolved on drug entrapment by the NPs. In aqueous media, butylcyanoacrylate polymerizes and PCL precipitates, whereas in the organic phase both the butylcyanoacrylate monomer and PCL dissolve (see "MATERIALS AND METHODS"). Tables I and II show the amount of drug entrapped by PBCA and PCL NPs, respectively, as a function of the 5-FU concentration. Independent of the type of polymeric particle, both the 5-FU entrapment efficiency (\%) and 5-FU-loading values $(\%)$ were significantly greater when the anticancer drug was added to the organic phase, whatever the initially fixed 5-FU concentration. For instance, in the case of PBCA NPs, when the initial drug concentration was $0.01 \mathrm{M}$ these parameters rose from $\approx 59.3 \%$ and $\approx 7.7 \%$ (when 5 -FU was dissolved to the aqueous media) to $\approx 73.8 \%$ and $\approx 9.6 \%$ (when 5-FU was incorporated within the organic phase), respectively. With respect to PCL NPs, when the initial drug concentration was $0.01 \mathrm{M}$, these parameters rose from $\approx 66.5 \%$ and $\approx 21.6 \%$ (when 5 -FU was added to the aqueous media) to $\approx 82.4 \%$ and $\approx 26.8 \%$ (when 5 -FU was dissolved in the organic phase), respectively. Such behavior is most likely a consequence of the difficulty experienced by 5-FU molecules in escaping from the polymeric matrices after they have been in deep contact with the butylcyanoacrylate monomer/\&caprolactone polymer. In addition, 5-FU loading to the NPs may be electrostatically favored: electrostatic attractive forces may exist between the positively charged drug molecules (generated by the protonation of the $-\mathrm{NH}$ group of the chemical structure) and the negatively charged NPs. Finally, the 5-FU concentration positively influenced the efficiency of drug entrapment into both types of polymeric NPs.

Regarding the influence of the surfactant on 5-FU entrapment by the polymeric NPs (Tables I and II), it was observed that the use of dextran-70 (within the concentration range tested) ensured the formation of homogeneous distributions of both 5-FU-loaded PBCA NPs and 5-FU-loaded PCL NPs, with reduced size and highly uniform, but without significantly influencing the drug entrapment efficiency and drug-loading values. Conversely, 5-FU entrapment was clearly lower in the absence of dextran-70. In fact, yields (\%) of 5FU-loaded PBCA NPs and 5-FU-loaded PCL NPs production were always $>90 \%$ in all the formulations prepared with dextran-70 but decreased to $\leq 6 \%$ in the absence of this surfactant. Similarly, butylcyanoacrylate monomer $/ \varepsilon-$ caprolactone polymer concentrations did not significantly influence the entrapment of 5-FU within the corresponding NPs (Tables I and II).

Finally, results from the electrophoretic characterization of the NPs clearly highlighted the great similarity between the $\zeta$ values of blank PBCA (and PCL) NPs and 5-FU-loaded PBCA (and PCL) NPs (Tables I and II): from an electrokinetic point of view, blank and drug-loaded NPs were indistinguishable. Therefore, and given the extreme sensitivity of electrophoresis to minute changes in the surface of nanosystems, this technique was satisfactorily utilized to estimate the type of drug incorporation to the NPs (drug surface adsorption $v s$. drug entrapment within the NP matrix). Given the fact that the $\zeta$ values of the NPs did not change upon 5-FU incorporation, it could be assumed that the molecules of chemotherapy agent were very efficiently entrapped within both types of polymeric nanomatrices.

Antiproliferative and in vivo tumor growth inhibition studies were performed using the NPs with the greatest 5-FU entrapment efficiencies, i.e., $\approx 73.8 \%$ for PBCA NPs (Table I) and $\approx 82.4 \%$ for PCL NPs (Table II).

\section{5-Fluorouracil Release from Poly(butylcyanoacrylate) and Poly $(\varepsilon$-caprolactone) Nanoparticles}

5-FU release at $\mathrm{pH} 7.4$ from PBCA (and PCL) NPs showed a biphasic process, typical of these polymers (18,30-33). Such a sustained drug-release profile was characterized by an initial rapid (burst) 5 -FU release phase (up to $\approx 27 \%$ and $\approx 16 \%$ in from PBCA NPs and PCL NPs in $3 \mathrm{~h}$, respectively), with the remaining 5-FU molecules being released in a more sustained manner (over a period of 93 and $117 \mathrm{~h}$ from PBCA NPs and PCL NPs, respectively) (Fig. 1b). Consequently, it may be concluded that the majority of the drug molecules were entrapped within the polymeric network rather than adsorbed onto the particle surface.

\section{In Vitro Cytotoxicity of Poly(butylcyanoacrylate)} and Poly( $\varepsilon$-caprolactone) Nanoparticles

Before carrying out the in vitro tests on antitumor activity, the toxicity of blank PBCA NPs and blank PCL NPs was investigated in vitro. Both PBCA and PCL NPs proved to be nontoxic in T-84, HT-29, and CCD-18 cell lines at the different drug equivalent concentrations tested (Fig. 2). Only PCL NPs showed some toxicity at the greatest concentration in the MC-38 $(3 \mu \mathrm{M})$ and HCT-15 $(20 \mu \mathrm{M})$ cell lines, resulting in reductions of $16.3 \%$ and $23.2 \%$ in the relative proliferation values, respectively $(p<0.05)$ (Fig. 2). Therefore, it can be assumed that both polymeric nanosystems present an adequate biocompatibility and safety for drug delivery purposes.

\section{Antiproliferative Effect of Poly(butylcyanoacrylate) and Poly $(\varepsilon$-caprolactone) Nanoparticles Loaded with 5-Fluorouracil}

Figures 3 and 4, respectively, demonstrate that both 5FU-loaded PBCA NPs and 5-FU-loaded PCL NPs can improve significantly the antiproliferative effect of the drug in comparison with free 5-FU. The $\mathrm{IC}_{50}$ values of free 5-FU in T-84, HT-29, HCT-15, and CCD-18 were found to be 3.60 , $3.58,7.59$, and $11.91 \mu \mathrm{M}$, respectively. In contrast, and after $72 \mathrm{~h}$ of exposure, 5-FU-loaded PBCA NPs exhibited a $\mathrm{IC}_{50}$ decrease which was particularly significant in T-84 colon cancer cells $\left(\mathrm{IC}_{50}, 0.085 \mu \mathrm{M}, \approx 42\right.$-fold decrease in the $\mathrm{IC}_{50}$ of free 5-FU; Fig. 3a), compared with HT-29 colon cancer cells $\left(\mathrm{IC}_{50}, 0.53 \mu \mathrm{M}, \approx 7\right.$-fold decrease in the $\mathrm{IC}_{50}$ of free 5 -FU; Fig. $3 b), \mathrm{HCT}-15$ colon cancer cells $\left(\mathrm{IC}_{50}, 0.76 \mu \mathrm{M}, \approx 10\right.$-fold 
a

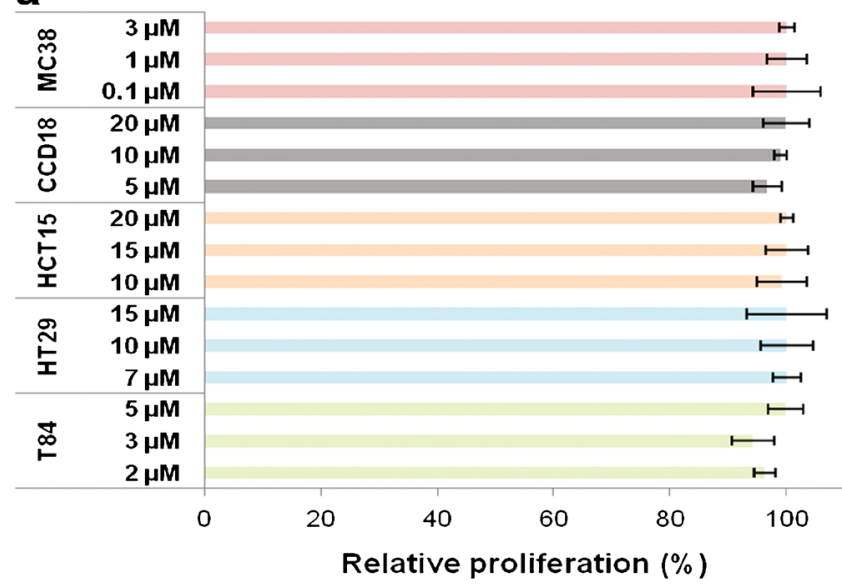

b

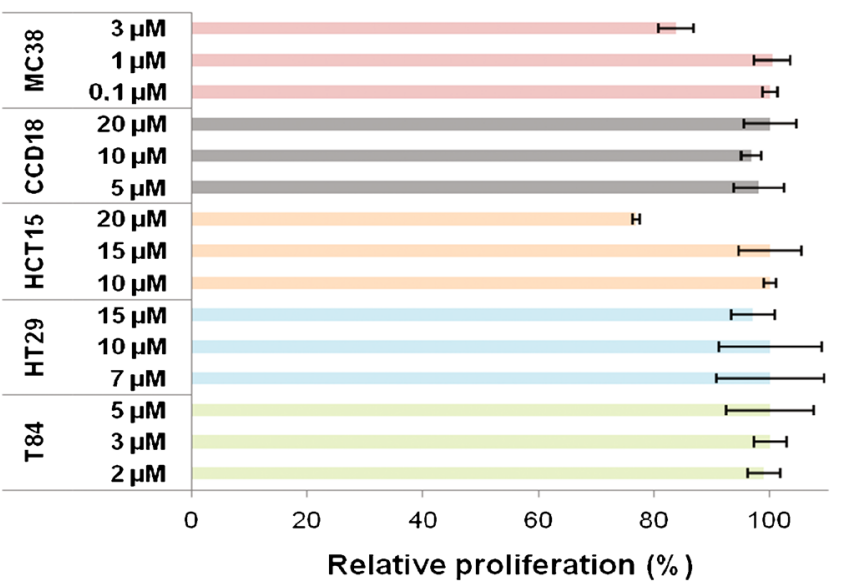

Fig. 2. In vitro cytotoxicity of PBCA (a) and PCL NPs (b) in colon cells. Growth of MC-38, CCD-18, HCT-15, HT-29, and T-84 cell lines was evaluated after $72 \mathrm{~h}$ of exposure to a wide range of NP concentrations $(0.1-20 \mu \mathrm{M})$. Data represents the mean value \pm SD of quadruplicate cultures

decrease in the $\mathrm{IC}_{50}$ of free 5-FU; Fig. 3c), CCD-18 normal colon cells $\left(\mathrm{IC}_{50}, 2.8 \mu \mathrm{M}, \approx 4\right.$-fold decrease in the $\mathrm{IC}_{50}$ of free 5-FU; Fig. 3d), and MC-38 mouse colon cancer cells ( $\mathrm{IC}_{50}$, $0.068 \mu \mathrm{M}, \approx 3$-fold decrease in the $\mathrm{IC}_{50}$ of free 5-FU; Fig. 3e).

Similar results were obtained with 5-FU-loaded PCL NPs, $\mathrm{IC}_{50}$ of $0.08 \mu \mathrm{M}$ in T-84 cells $(\approx 45$-fold decrease in the $\mathrm{IC}_{50}$ of free 5-FU; Fig. $\left.4 \mathrm{a}\right), \mathrm{IC}_{50}$ of $0.76 \mu \mathrm{M}$ in HT-29 cells $\left(\approx 5\right.$-fold decrease in the $\mathrm{IC}_{50}$ of free 5-FU; Fig. $\left.4 \mathrm{~b}\right), \mathrm{IC}_{50}$ of $0.74 \mu \mathrm{M}$ in HCT-15 cells $\left(\approx 10\right.$-fold decrease in the $\mathrm{IC}_{50}$ of free 5-FU; Fig. 4c), $\mathrm{IC}_{50}$ of $2.7 \mu \mathrm{M}$ in CCD-18 cells ( $\approx 4.5$-fold decrease in the $\mathrm{IC}_{50}$ of free 5-FU; Fig. 4d), and $\mathrm{IC}_{50}$ of $0.068 \mu \mathrm{M}$ in MC-38 cells $\left(\approx 4\right.$-fold decrease in the $\mathrm{IC}_{50}$ of free 5-FU; Fig. 4e).

In Vivo Tumor Growth Inhibition with Poly(butylcyanoacrylate) and Poly( $\varepsilon$-caprolactone) Nanoparticles Loaded with 5-Fluorouracil

Figure 5 shows that both PBCA and PCL NPs loaded with 5-FU induced a significant reduction in tumor volumes after 45 days of treatment compared with free 5-FU $(p<0.05)$, i.e., a $51 \%$ (Fig. 5a) and a $64.5 \%$ (Fig. 5b) reduction, respectively. Comparing the two types of 5-FU-loaded NPs, treatment with PCL NPs caused a $13.5 \%$ greater reduction in tumor size than PBCA NPs $(p<0.05)$. Finally, tumor evolution in mice treated with blank PBCA NPs and with blank PCL NPs was quite similar to the control group (untreated mice).

\section{Survival Analysis}

Despite the slight control over tumor volume evolution developed by free 5-FU (Fig. 5), it failed in increasing mice survival compared with the control group (Fig. 6). In contrast, 5-FU-loaded PBCA NPs (Fig. 6a) and 5-FU-loaded PCL NPs (Fig. 6b) significantly prolonged mice survival $(p<0.05)$ in comparison with untreated mice and mice treated with free 5FU. It may be the consequence of the great control over tumor growth displayed by both 5-FU-loaded nanosystems. Finally, no significant differences were observed between both 5-FU-loaded nanoformulations in terms of mice survival.

\section{In Vivo Toxicity}

No loss of body mass was reported in mice treated with blank (5-FU unloaded) NPs in comparison with the control (untreated) group (Fig. 7). Regarding mice treated with either free 5-FU, 5-FU-loaded PBCA NPs, or 5-FU-loaded PCL NPs, a similar loss in body mass was observed compared with controls $(p<0.001)$, suggesting that loading 5 -FU within both polymeric NPs did not increase drug's toxicity (Fig. 7).

\section{DISCUSSION}

Current chemotherapy against colon cancer is not fully effective, especially during advanced stages of the disease (34). Antitumor drugs, including 5-FU, can often cause severe side effects and compromise the patients' quality of life. Therefore, it is necessary to develop new therapeutic strategies, including the use of drug-loaded nanoplatforms, to maximize the cytotoxicity (and specificity) of chemotherapy agents, while keeping drug aggression toward healthy tissues to a minimum (10). In this work, we present two nanoformulations that may contribute to the optimization of 5-FU-based colon cancer treatments.

Synthesis methodologies of 5-FU-loaded PBCA NPs and 5-FU-loaded PCL NPs were based on the emulsion polymerization of the butylcyanoacrylate monomer in an aqueous solution (22) and on the interfacial polymer disposition, respectively $(18,27)$. Both methods generated biodegradable 5 -FU-loaded particles with an average size $\leq 100 \mathrm{~nm}$ (Tables I and II), which could be deemed appropriate to facilitate their cellular uptake thus resulting in a considerable accumulation of drug molecules within malignant cells. In fact, particle diameters ranging from 100 to $200 \mathrm{~nm}$ have been associated with cell internalization by endocytosis, while larger particles can be internalized by phagocytosis (35).

Optimum preparation conditions were considered to be those that reported the greatest 5-FU entrapment efficiencies and 5-FU loading values (Tables I and II). Furthermore, given the similarities between the $\zeta$ values of blank NPs and of the corresponding drug-loaded NPs (Tables I and II), it may be assumed that the 5-FU molecules were efficiently entrapped within the particle matrices rather than just 

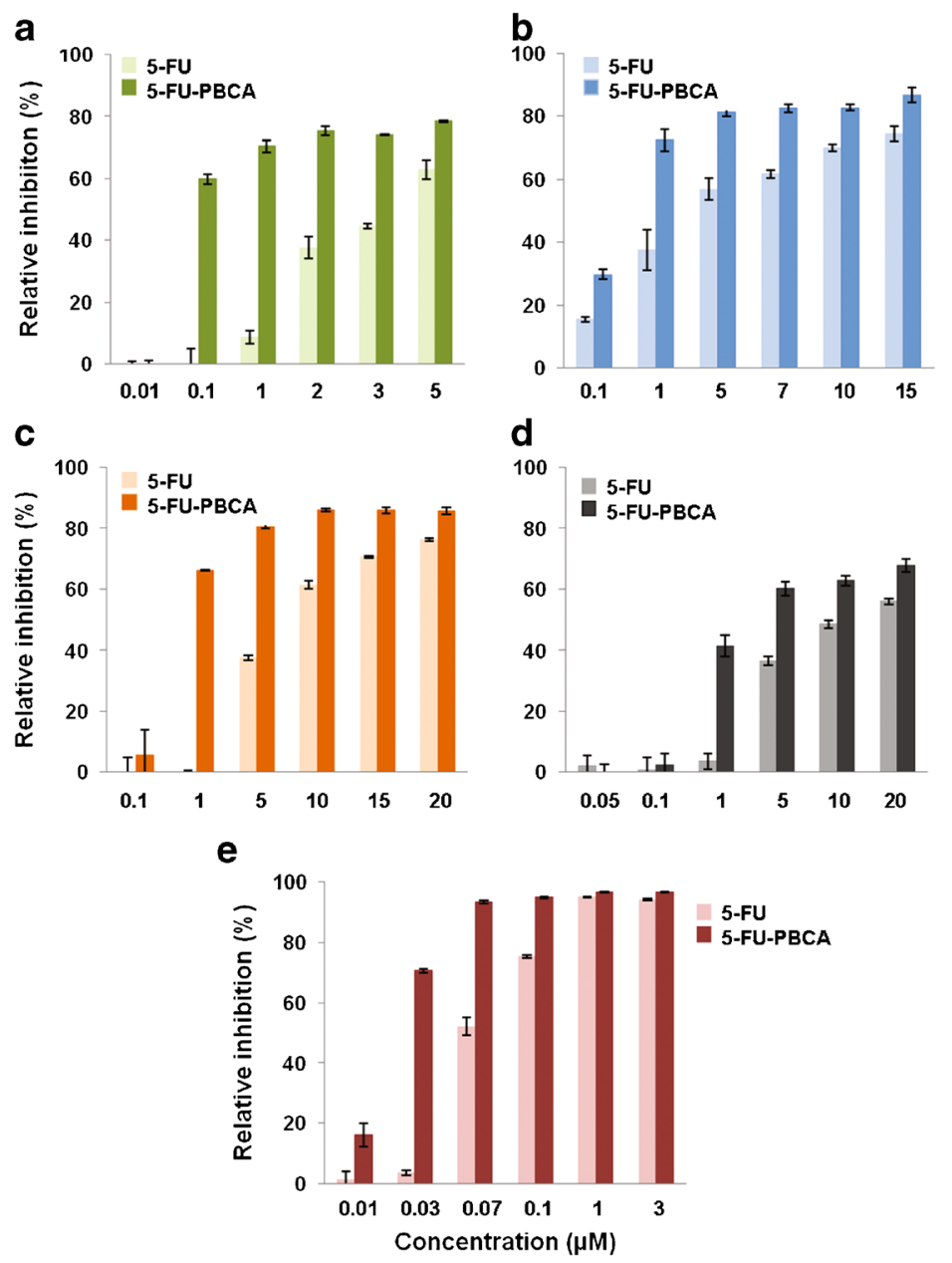

Fig. 3. In vitro cytotoxicity of 5-FU-loaded PBCA NPs (5-FU-PBCA) in colon cells. Growth inhibition of T-84 (a), HT-29 (b), HCT-15 (c), CCD-18 (d), and MC-38 (e) was evaluated after $72 \mathrm{~h}$ and compared with that of free 5FU. The survival rate was determined by normalizing the absorbance of controls to $100 \%$. Data represents the mean value \pm SD of quadruplicate cultures

adsorbed onto the surfaces. Finally, 5-FU release from PBCA and PCL NPs exhibited a biphasic (and sustained) profile (Fig. 1). The fast drug release during the first phase could be due to the loss of surface associated and/or poorly entrapped 5-FU molecules, which rapidly diffused into the release medium. 5-FU release during the slower second phase, however, may correspond to the drug fraction deeply embedded within the polymeric nanomatrices, which may follow a longer diffusion path before being released into the surrounding medium. In the specific case of PBCA NPs, drug release could be the consequence of either particle disintegration due to surface erosion, drug diffusion through the polymeric matrix, or both $(30,32)$. Whereas, with respect to PCL NPs, 5-FU release during this second phase could be due to drug diffusion through the polymeric matrix as opposed to polymer disintegration, which for PCL is a very slow process in an aqueous medium given its considerable hydrophobic character $(18,31,33)$.

Comparison of data included in Tables I and II and in Fig. 1 can be used to check the great similarities between geometry (size and shape), drug-loading capabilities, and drug-release profiles of PBCA and PCL particles. In fact, statistical treatment of data helped us in establishing that the differences were not statistically significant. On the opposite, differences between the surface electrical charge of PBCA and PCL NPs were relevant (Tables I and II): PCL NPs were less negative, this postulating a reduced interaction with the reticuloendothelial system and, therefore, a more appropriate in vivo fate (for drug delivery purposes) compared with the PBCA NPs (i.e., greater accumulation into the tumor site) (35). Finally, our research group has previously published information on the surface thermodynamics of both nanoformulations: they can be considered to be hydrophobic $(15,36)$.

The association of 5-FU molecules with nanocarriers has yielded diverse results against colon cancer cell lines (37-40). For instance, Jain and Jain (41) demonstrated that chitosan NPs coupled to hyaluronic acid and loaded with 5-FU can moderately (2.6 times) increase the drug's cytotoxicity to HT29 colon cancer cells. These results can be improved when this nanocarrier is surface functionalized with folate moieties (42). Nanocarriers based on copolymers such as $\operatorname{poly}(\gamma$ benzyl-L-glutamate) and poly(ethylene glycol) can increase 

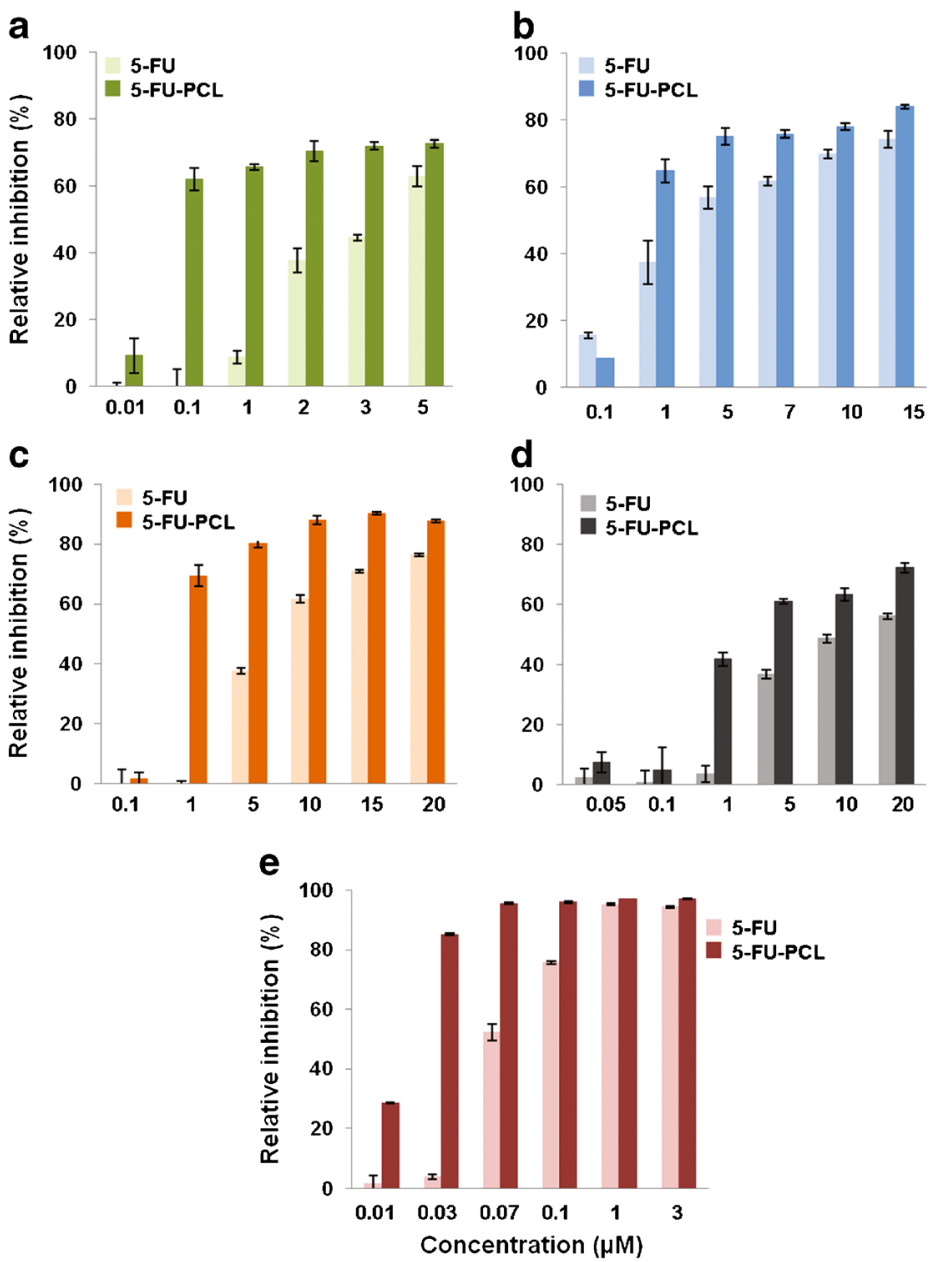

Fig. 4. In vitro cytotoxicity of 5-FU-loaded PCL NPs (5-FU-PCL) in colon cells. Growth inhibition of T-84 (a), HT-29 (b), HCT-15 (c), CCD-18 (d), and MC-38 (e) was evaluated after $72 \mathrm{~h}$ and compared with that of free 5-FU. The survival rate was determined by normalizing the absorbance of controls to $100 \%$. Data represents the mean value \pm SD of quadruplicate cultures

the plasma half-life of 5-FU, thus inducing a greater growth inhibition of LoVo colon cancer cells (43). Recently, Dutta et al. (39) reduced HT-29 cell viability using 5-FU in superparamagnetic iron oxides encapsulated pectin nanocarriers and solid lipid NPs. However, neither of these nanostrategies against colon cancer have been validated in vivo. Our in vitro results demonstrated that 5-FU-loaded PCL NPs were able to decrease the $\mathrm{IC}_{50}$ of 5-FU and thus its antiproliferative effect. Particularly relevant were the results obtained against $\mathrm{T}-84$ cells (i.e., $\approx 45$-fold decrease in the $\mathrm{IC}_{50}$ of free 5-FU). In addition, PCL NPs did not induce any cell toxicity as previously reported by Kuo-Yung et al. (44). Very little data is available on the use of 5-FU-loaded PCL nanoparticulate systems against colon cancer cells. However, Ortiz et al. (18) demonstrated that PCL NPs can increase the antitumor effect of 5-FU against SW480 cells, and Zhang et al. (9) showed that PCL NPs surface functionalized with folate moieties can improve the activity of 5-FU against colon cancer cells. Furthermore, PCL NPs loaded with doxifluridine (a prodrug of 5-FU) have been reported to exhibit an important activity against HT-29 colon cancer cells (45). With respect to 5-FU-loaded PBCA NPs, they have been shown to be well tolerated in the case of superficial basal cell carcinoma (46).
In the present investigation, the in vitro antiproliferative effects of 5-FU-loaded PBCA NPs and 5-FU-loaded PCL NPs could be considered to be quiet similar (please check Figs. 3 and 4 and $\mathrm{IC}_{50}$ values reported above). In any case, both 5FU-loaded nanosystems have provided a greater antiproliferative effect against colon cancer cells than previously developed 5-FU nanoformulations, e.g., PLGA NPs which can decrease the $\mathrm{IC}_{50}$ of the drug in HT-29 cells only by a factor of 4 (47) or chitosan NPs which only yielded a $20 \%$ increase in the inhibition of SW480 colon cancer cell proliferation compared with the free drug (40). The reduction in RP (\%) caused by the 5-FU-loaded PBCA and PCL NPs could be the consequence of a faster (and more intense) 5-FU internalization by malignant cells, therefore facilitating greater drug concentrations within the cancer cells. Furthermore, NP internalization within cancer cells depends not only on their hydrophilic/hydrophobic character and physical chemistry (i.e., size and surface charge) but also on the endocytosis processes involved which can be considered to be more important in tumor cells $(48,49)$.

To ensure the therapeutic potential of 5-FU-loaded PBCA and PCL NPs in colon cancer, we analyzed their behavior in vivo. It was observed that nanoparticulate 

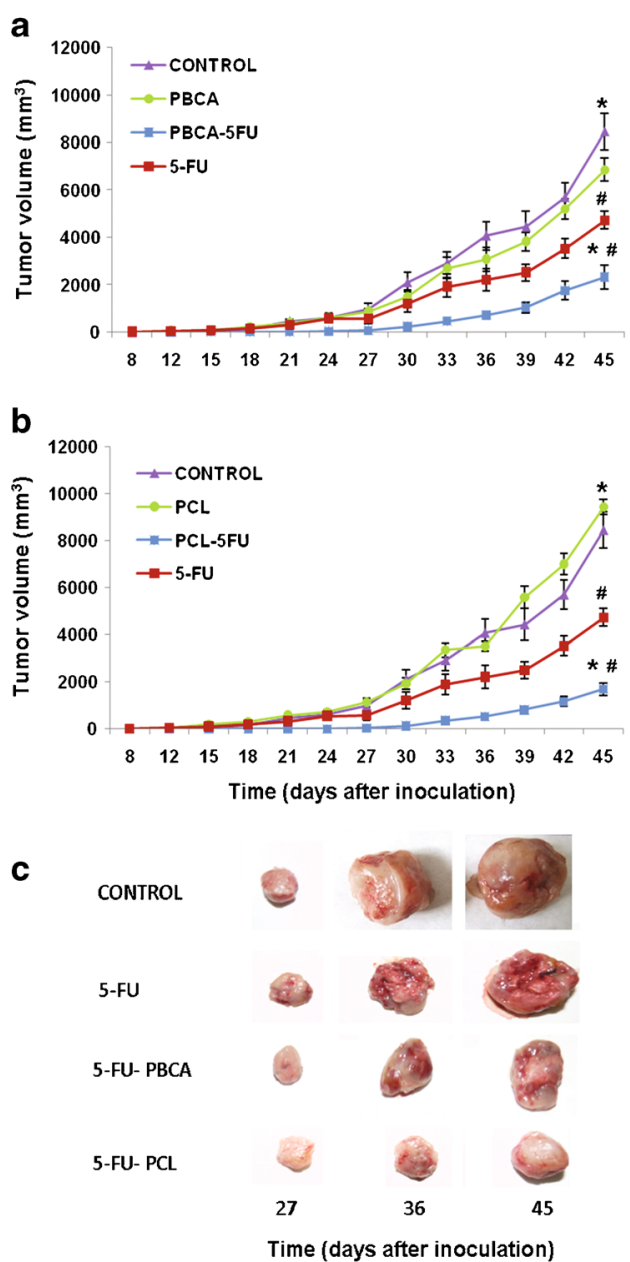

Fig. 5. Tumor growth inhibition induced by 5-FU-loaded PBCA NPs (5-FU-PBCA) (a) and 5-FU-loaded PCL NPs (5-FU-PCL) (b) and representative gross appearance of tumors excised from treated mice after 27, 36, and 45 days of treatment and from untreated mice at the same time intervals (c). Both types of 5-FU-loaded NPs exhibited significant tumor inhibition compared with the control $\left({ }^{*} p<0.01\right)$ and to free 5 -FU $\left({ }^{\#} p<0.05\right)$. Data represents the mean value \pm standard error of the mean (SEM; $n=10$ )

systems induced a significant reduction in the tumor volume in comparison with the free drug (Fig. 5). Interestingly, tumor volumes were more efficiently reduced in mice treated with 5FU-loaded PCL NPs (64\%) than in those treated with 5-FUloaded PBCA NPs (51\%). Such 5-FU activity can be assumed to be more significant than the one recently reported for 5FU-loaded chitosan NPs in an orthotropic mouse liver cancer model (50).

Although free 5-FU can reduce significantly the tumor volume (Fig. 5), it did not induce a significant difference in the survival rates compared with control mice (Fig. 6). This may be due to the low specificity of 5-FU as it affects not only tumor regions but also healthy tissues (i.e., gastrointestinal tissues) (51). On the contrary, mice survival rate was significantly prolonged when using both 5-FU-loaded nanoformulations compared with controls (untreated, blank NPs, and free drug). The mechanism by which the 5-FUloaded NPs increase drug activity is not fully understood, but their physicochemical properties, essentially their
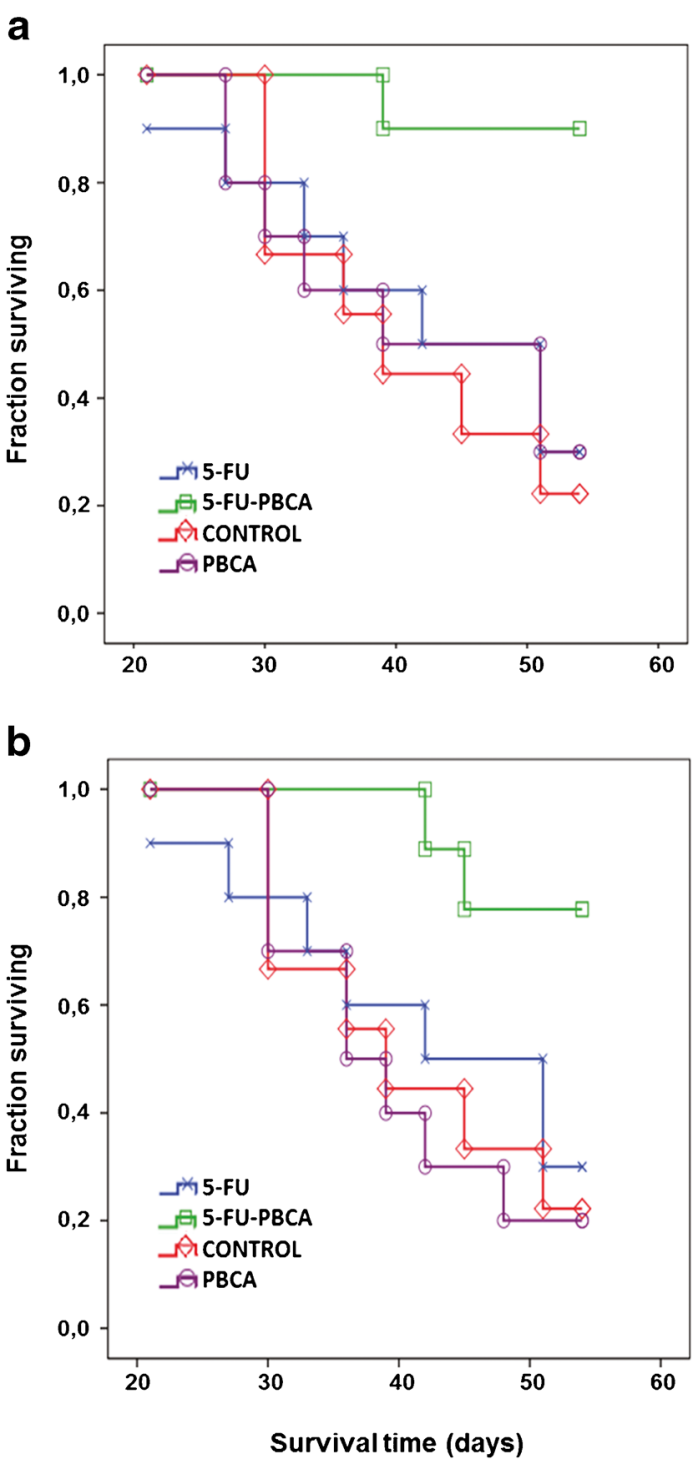

Fig. 6. Survival curves calculated by the Kaplan Meier method. Data was analyzed according to mouse survival after treatment with 5-FUloaded PBCA NPs (5-FU-PBCA) (a) and 5-FU-loaded PCL NPs (5$F U-P C L)(\mathbf{b})$. The fraction of surviving mice were compared between groups using the log-rank test $(p<0.05)$. Both types of 5 -FU-loaded NPs exhibited an increase in survival rates compared with the control and to free 5 -FU $(p<0.05)$

nanosize may be responsible for an increased accumulation/concentration into malignant tissues, thanks to the enhanced permeation and retention (EPR) effect (52). This phenomenon is based on the aberrant ("leaky") structure of blood vessels irrigating tumor tissues (53), in which large gaps between endothelial cells and discontinuities in the basement membrane can be found, being responsible for the alteration of the normal diffusion of macromolecules across the endothelium. Furthermore, the clearance of macromolecules is limited by the reduced lymphatic circulation which is characteristic of tumor tissues (54). Future studies will be necessary to elucidate the mechanism by which both 5-FU-loaded PBCA NPs and 5FU-loaded PCL NPs can increase the in vivo efficacy of 5FU. 

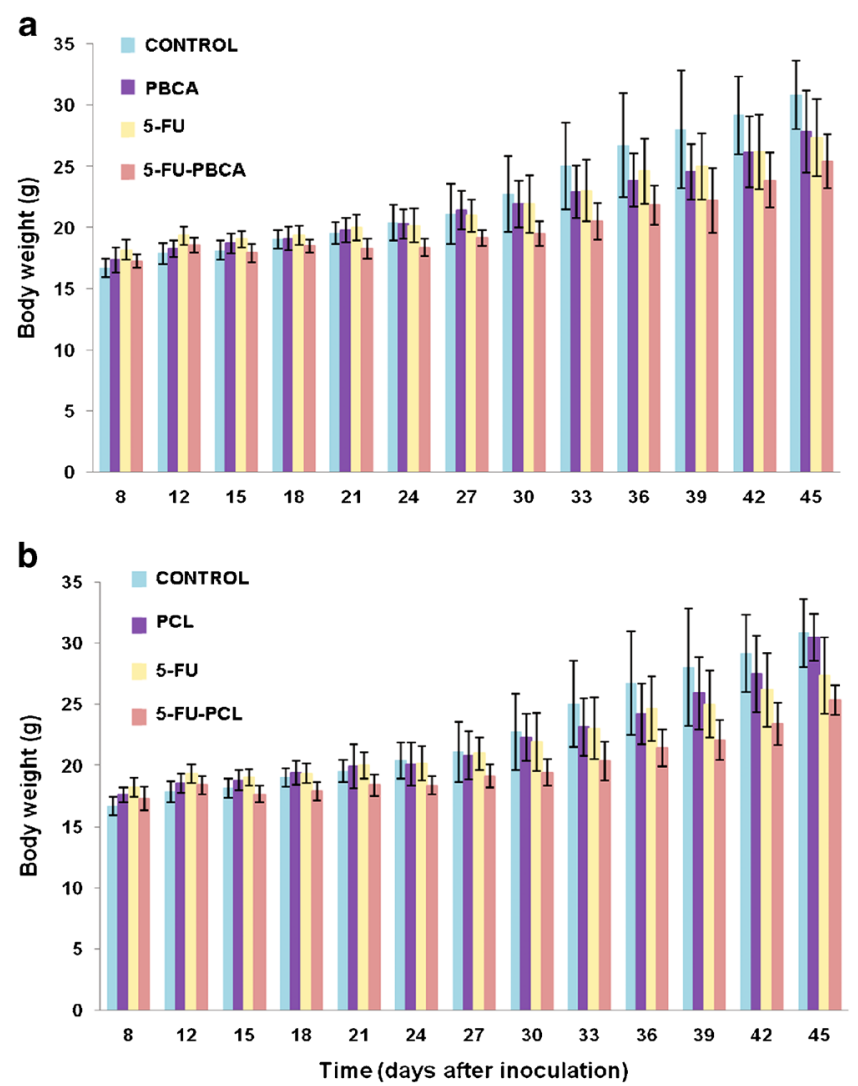

Fig. 7. Evolution of the body mass of immunocompetent C57BL/6 mice bearing subcutaneous MC38 tumors during, and after, treatment with 5-FU-loaded PBCA NPs (5-FU-PBCA) (a) and with 5-FUloaded PCL NPs (5-FU-PCL) (b). The masses of the mice and the tumors were measured as described in "MATERIALS AND METHODS." Treatment with blank NPs induced similar losses in body mass as those produced by the controls. Free 5-FU and both 5FU-loaded NPs treatments induced similar loss in mouse body mass in relation to the controls $(p<0.001)$. Data represents mean value \pm SD $(n=10)$

\section{CONCLUSIONS}

A reproducible formulation methodology has been developed to obtain PBCA and PCL nanomatrices for the efficient delivery of 5-FU, on the basis of an emulsion polymerization procedure and on an interfacial polymer disposition method, respectively. Preclinical results demonstrate that both 5-FU-loaded NPs can significantly inhibit the proliferation of the human and mice colon cancer cell lines being tested. Greater tumor growth inhibition and mice survival rates were obtained when using these nanoparticulate systems compared with the free drug. Thus, these results suggest that PBCA and PCL nanoparticulate systems may open a promising possibility to optimize the delivery of 5-FU to malignant cells and, consequently, the chemotherapy of advanced or recurrent colon cancer.

\section{ACKNOWLEDGMENTS}

This investigation was funded by FEDER, Plan Nacional de Investigación Científica, Desarrollo e Innovación Tecnológica (I+D+i), Instituto de Salud Carlos III (FIS): projects PI11/01862 and PI11/02571, and by the Consejería de Salud de la Junta de Andalucía: project PI-0049 and P11CTS-7649 (NPs synthesis).

Conflict of Interest The authors declare that there are no conflicts of interest.

\section{REFERENCES}

1. Labianca R, Beretta GD, Kildani B, Milesi L, Merlin F, Mosconi S, et al. Colon cancer. Crit Rev Oncol Hematol. 2010;74:106-33.

2. Zhang N, Yin Y, Xu SJ, Chen WS. 5-Fluorouracil: mechanisms of resistance and reversal strategies. Molecules. 2008;13:1551-69.

3. Van Cutsem E, Köhne CH, Hitre E, Zaluski J, Chang Chien CR, Makhson A, et al. Cetuximab and chemotherapy as initial treatment for metastatic colorectal cancer. N Engl J Med. 2009;360:1408-17.

4. Peters GJ, Backus HH, Freemantle S, van Triest B, CodacciPisanelli G, van der Wilt CL, et al. Induction of thymidylate synthase as a 5-fluorouracil resistance mechanism. Biochim Biophys Acta. 2002;1587:194-205.

5. Guichard SM, Macpherson JS, Thurston DE, Jodrell DI. Influence of P-glycoprotein expression on in vitro cytotoxicity and in vivo antitumor activity of the novel pyrrolobenzodiazepine dimer SJG-136. Eur J Cancer. 2005;41:1811-8.

6. Song M, Zang W, Zhang B, Cao J, Yang G. GCS overexpression is associated with multidrug resistance of human HCT-8 colon cancer cells. J Exp Clin Cancer Res. 2012;31:23.

7. Wang AZ, Langer R, Farokhzad OC. Nanoparticle delivery of cancer drugs. Annu Rev Med. 2012;63:185-8.

8. Patel NR, Pattni BS, Abouzeid AH, Torchilin VP. Nanopreparations to overcome multidrug resistance in cancer. Adv Drug Deliv Rev. 2013;65:1748-62.

9. Zhang Y, Li J, Lang M, Tang X, Li L, Shen X. Folatefunctionalized nanoparticles for controlled 5-fluorouracil delivery. J Colloid Interface Sci. 2011;354:202-9.

10. Prados J, Melguizo C, Ortiz R, Perazzoli G, Cabeza L, Alvarez $\mathrm{PJ}$, et al. Colon cancer therapy: recent developments in nanomedicine to improve the efficacy of conventional chemotherapeutic drugs. Anti Cancer Agents Med Chem. 2013;13:1204-16.

11. Rahman Z, Kohli K, Khar RK, Ali M, Charoo NA, Shamsher AA. Characterization of 5-fluorouracil microspheres for colonic delivery. AAPS PharmSciTech. 2006;7:47-53.

12. Singh R, Lillard Jr JW. Nanoparticle-based targeted drug delivery. Exp Mol Pathol. 2009;86:215-23.

13. Stella B, Arpicco S, Rocco F, Marsaud V, Renoir JM, Cattel L, et al. Encapsulation of gemcitabine lipophilic derivatives into polycyanoacrylate nanospheres and nanocapsules. Int J Pharm. 2007:344:71-7.

14. Zhang J, Men K, Gu Y, Wang X, Gou M, Guo G, et al. Preparation of core cross-linked PCL-PEG-PCL micelles for doxorubicin delivery in vitro. J Nanosci Nanotechnol. 2011;11:5054-61.

15. Arias JL, López-Viota M, Sáez-Fernández E, Ruiz MA. Formulation and physicochemical characterization of poly(epsilon-caprolactone) nanoparticles loaded with ftorafur and diclofenac sodium. Colloids Surf B: Biointerfaces. 2010;75:204-8.

16. Chen W, Wu Z, Yang H, Guo S, Li D, Cheng L. In vitro and in vivo evaluation of injectable implants for intratumoral delivery of 5-fluorouracil. Pharm Dev Technol. 2014;19:223-31.

17. Gong C, Wang C, Wang $\mathrm{Y}, \mathrm{Wu} \mathrm{Q}$, Zhang $\mathrm{D}$, Luo $\mathrm{F}$, et al. Efficient inhibition of colorectal peritoneal carcinomatosis by drug loaded micelles in thermosensitive hydrogel composites. Nanoscale. 2012;4:3095-104.

18. Ortiz R, Prados J, Melguizo C, Arias JL, Ruiz MA, Alvarez PJ, et al. 5-Fluorouracil-loaded poly( $\varepsilon$-caprolactone) nanoparticles 
combined with phage E gene therapy as a new strategy against colon cancer. Int J Nanomedicine. 2012;7:95-107.

19. Duan J, Zhang Y, Han S, Chen Y, Li B, Liao M, et al. Synthesis and in vitro/in vivo anti-cancer evaluation of curcumin-loaded chitosan/poly(butyl cyanoacrylate) nanoparticles. Int J Pharm. 2010;400:211-20.

20. He M, Zhao Z, Yin L, Tang C, Yin C. Hyaluronic acid coated poly(butyl cyanoacrylate) nanoparticles as anticancer drug carriers. Int J Pharm. 2009;373:165-73.

21. Ren F, Chen R, Wang Y, Sun Y, Jiang Y, Li G. Paclitaxel-loaded poly(n-butylcyanoacrylate) nanoparticle delivery system to overcome multidrug resistance in ovarian cancer. Pharm Res. 2011;28:897-906.

22. Arias JL, Reddy LH, Couvreur P. Polymeric nanoparticulate system augmented the anticancer therapeutic efficacy of gemcitabine. J Drug Target. 2009;17:586-98.

23. Kreuter J, Gelperina S. Use of nanoparticles for cerebral cancer. Tumori. 2008;94:271-7.

24. Wohlfart S, Khalansky AS, Bernreuther C, Michaelis M, Cinatl $\mathrm{Jr} \mathrm{J}$, Glatzel $\mathrm{M}$, et al. Treatment of glioblastoma with poly(isohexyl cyanoacrylate) nanoparticles. Int J Pharm. 2011;415:244-51.

25. Mulik RS, Mönkkönen J, Juvonen RO, Mahadik KR, Paradkar AR. ApoE3 mediated polymeric nanoparticles containing curcumin: apoptosis induced in vitro anticancer activity against neuroblastoma cells. Int J Pharm. 2012;437:29-41.

26. Vauthier C, Dubernet C, Chauvierre C, Brigger I, Couvreur P. Drug delivery to resistant tumors: the potential of poly(alkyl cyanoacrylate) nanoparticles. J Control Release. 2003;93:151-60.

27. Sinha VR, Bansal K, Kaushik R, Kumria R, Trehan A. Polyepsilon-caprolactone microspheres and nanospheres: an overview. Int J Pharm. 2004;278:1-23.

28. O'Brien RW, White LR. Electrophoretic mobility of a spherical colloidal particle. J Chem Soc Faraday Trans. 1978;74:1607-26.

29. Prados J, Melguizo C, Ortiz R, Boulaiz H, Carrillo E, Segura A, et al. Regression of established subcutaneous B16-F10 murine melanoma tumors after gef gene therapy associated with the mitochondrial apoptotic pathway. Exp Dermatol. 2010;19:363-71.

30. Arias JL, Ruiz MA, López-Viota M, Delgado AV. Poly(alkylcyanoacrylate) colloidal particles as vehicles for antitumour drug delivery. A comparative study. Colloids Surf B: Biointerfaces. 2008;62:64-70.

31. Gibaud S, Jabir Al Awwadi N, Ducki C, Astier A. Poly(epsiloncaprolactone) and Eudragit microparticles containing fludrocortisone acetate. Int J Pharm. 2004;269:491-508.

32. Graf A, McDowell A, Rades T. Poly(alkylcyanoacrylate) nanoparticles for enhanced delivery of therapeutics-is there real potential? Expert Opin Drug Deliv. 2009;6:371-87.

33. Pohlmann AR, Fonseca FN, Paese K, Detoni CB, Coradini K, Beck RC, et al. Poly( $\varepsilon$-caprolactone) microcapsules and nanocapsules in drug delivery. Expert Opin Drug Deliv. 2013;10:623-38.

34. Meyerhardt JA, Mayer RJ. Systemic therapy for colorectal cancer. N Engl J Med. 2005;352:476-87.

35. Decuzzi P, Pasqualini R, Arap W, Ferrari M. Intravascular delivery of particulate systems: does geometry really matter? Pharm Res. 2009;26:235-43.

36. Arias JL, Gallardo V, Linares-Molinero F, Delgado AV. Preparation and characterization of carbonyl iron/poly(butylcyanoacrylate) core/shell nanoparticles. J Colloid Interface Sci. 2006;299:599-607.
37. Serpe L, Catalano MG, Cavalli R, Ugazio E, Bosco O, Canaparo $\mathrm{R}$, et al. Cytotoxicity of anticancer drugs incorporated in solid lipid nanoparticles on HT-29 colorectal cancer cell line. Eur J Pharm Biopharm. 2004;58:673-80.

38. Yassin AE, Anwer MK, Mowafy HA, El-Bagory IM, Bayomi MA, Alsarra IA. Optimization of 5-flurouracil solid-lipid nanoparticles: a preliminary study to treat colon cancer. Int J Med Sci. 2010;7:398-408.

39. Dutta RK, Sahu S. Development of a novel probe sonication assisted enhanced loading of 5-FU in SPION encapsulated pectin nanocarriers for magnetic targeted drug delivery system. Eur J Pharm Biopharm. 2012;82:58-65.

40. Cheng $\mathrm{M}, \mathrm{Xu} \mathrm{H}$, Wang $\mathrm{Y}$, Chen $\mathrm{H}, \mathrm{He} \mathrm{B}$, Gao X, et al. Glycyrrhetinic acid-modified chitosan nanoparticles enhanced the effect of 5-fluorouracil in murine liver cancer model via regulatory T-cells. Drug Des Dev Ther. 2013;7:1287-99.

41. Jain A, Jain SK. In vitro and cell uptake studies for targeting of ligand anchored nanoparticles for colon tumors. Eur J Pharm Sci. 2008;35:404-16.

42. Li P, Wang Y, Zeng F, Chen L, Peng Z, Kong LX. Synthesis and characterization of folate conjugated chitosan and cellular uptake of its nanoparticles in HT-29 cells. Carbohydr Res. 2011;346:801-6.

43. Li S, Wang A, Jiang W, Guan Z. Pharmacokinetic characteristics and anticancer effects of 5-fluorouracil loaded nanoparticles. BMC Cancer. 2008;8:103-12.

44. Kuo-Yung C, Yu-Der L. Ring-opening polymerization of $\varepsilon^{-}$ caprolactone initiated by the antitumor agent doxifluridine. Acta Biomater. 2009;5:1075-81.

45. Wang J, Peng CA. Anticancer effectiveness of polymeric drug nanocarriers on colorectal cancer cells. Conf Proc IEEE Eng Med Biol Soc. 2011;2011:3249-52.

46. Hadjikirova M, Troyanova P, Simeonova M. Nanoparticles as drug carrier system of 5-fluorouracil in local treatment of patients with superficial basal cell carcinoma. J BUON. 2005;10:517-21.

47. Wang Y, Li P, Chen L, Gao W, Zeng F, Kong LX. Targeted delivery of 5-fluorouracil to HT-29 cells using high efficient folic acid-conjugated nanoparticles. Drug Deliv. 2015;22:191-8.

48. Harush-Frenkel O, Altschuler Y, Benita S. Nanoparticle-cell interactions: drug delivery implications. Crit Rev Ther Drug Carrier Syst. 2008;25:485-544.

49. Mosesson Y, Mills GB, Yarden Y. Derailed endocytosis: an emerging feature of cancer. Nat Rev Cancer. 2008;8:835-50.

50. Cheng M, Chen H, Wang Y, Xu H, He B, Han J, et al. Optimized synthesis of glycyrrhetinic acid-modified chitosan 5-fluorouracil nanoparticles and their characteristics. Int $\mathrm{J}$ Nanomedicine. 2014;9:695-710.

51. Llorca C, Esquerdo G, Cervera JM, Briceño HC, Calduch JV, Del Pino J. 5-Fluorouracil-induced small bowel toxicity in a patient with colorectal cancer. Clin Transl Oncol. 2005;7:356-7.

52. Moghimi SM, Hunter AC, Murray JC. Long-circulating and target-specific nanoparticles: theory to practice. Pharmacol Rev. 2001;53:283-318.

53. Baban DF, Seymour LW. Control of tumour vascular permeability. Adv Drug Deliv Rev. 1998;34:109-19.

54. Maeda H, Wu J, Sawa T, Matsumura Y, Hori K. Tumor vascular permeability and the EPR effect in macromolecular therapeutics: a review. J Control Release. 2000;65:271-84. 